\title{
GERMINAÇÃO DE SEMENTES DE Platymiscium floribundum VOG. (FABACEAE) SOB A INFLUÊNCIA DA LUZ E TEMPERATURAS
}

\author{
GERMINATION OF SEEDS OF Platymiscium floribundum VOG. (FABACEAE) UNDER THE \\ INFLUENCE OF TEMPERATURES AND LIGHT
}

\author{
Magnólia Martins Alves ${ }^{1}$ Edna Ursulino Alves ${ }^{2}$ Maria de Lourdes dos Santos Lima ${ }^{3}$ \\ Caroline Marques Rodrigues ${ }^{4}$ Bruno Ferreira da Silva ${ }^{5}$
}

\begin{abstract}
RESUMO
Platymiscium floribundum Vog., uma espécie florestal pertencente à família Fabaceae, apresenta grande potencial para exploração econômica e pode ser utilizada tanto no paisagismo como em reflorestamentos, na recuperação de áreas degradadas e de preservação permanente. Diante de sua importância, o trabalho teve como objetivo estudar a influência da luz e temperaturas na germinação de sementes de Platymiscium floribundum. Avaliou-se a germinação e vigor das sementes sob temperaturas de 25 e $30^{\circ} \mathrm{C}$ constantes e 20 $30^{\circ} \mathrm{C}$ alternada em diferentes regimes de luz: branca (LB), verde (LV), vermelha-distante (LVD), vermelha (LV) e ausência de luz (A). O delineamento experimental foi inteiramente ao acaso, em esquema fatorial 3 x 5, com quatro repetições de 25 sementes. As variáveis analisadas foram: germinação, primeira contagem de germinação, índice de velocidade de germinação (IVG), comprimento e massa seca de plântulas (raiz e altura da parte aérea). As sementes de Platymiscium floribundum expressam seu máximo vigor em ambiente iluminado independentemente da temperatura.
\end{abstract}

Palavras-chave: vigor; espécie florestal; fotoblastismo; jacarandá.

\begin{abstract}
Platymiscium floribundum Vog., a forest species belonging to the family Fabaceae, has great potential for economic exploitation and can be used both in landscape and in reforestation, in the restoration of degraded areas and permanent preservation.given its importance, this work was, it was aimed to study the influence of light and temperature on seed germination of Platymiscium floribundum. We evaluate the germination and vigor Under constant and alternate temperatures of 25 and $30^{\circ} \mathrm{C}$ in different light regimes: White (LB), green (LV), red-far (LVD), red (LV) and absence light (A). The experimental design was completely randomized in a factorial $3 \times 5$ with four replications of 25 seeds. The variables analyzed were: germination, first count of germination, germination speed index (IGV), length and seedling dry weight (root length, shoot length of seedlings). The seeds of Platymiscium floribundum express their maximum force in illuminated environment independent of the temperature.
\end{abstract}

Keywords: force; forest species; photoblastism; jacaranda.

1 Bacharel em Ecologia, Mestranda do Programa de Pós-graduação em Agronomia, Centro de Ciências Agrárias, Universidade Federal da Paraíba, Campus II, CEP 58397-000, Areia (PB), Brasil. magecologia@hotmail.com

2 Engenheira Agrônoma, Dra ${ }^{\mathrm{a}}$, Professora do Departamento de Fitotecnia e Ciências Ambientais, Centro de Ciências Agrárias, Universidade Federal da Paraíba, Caixa Postal 02, CEP 58397-000, Areia (PB), Brasil. ednaursulino@cca.ufpb.br

3 Graduanda em Agronomia, Departamento de Fitotecnia e Ciências Ambientais, Centro de Ciências Agrárias, Universidade Federal da Paraíba, Campus II, CEP 58397-000, Areia (PB), Brasil. lourdestoy@gmail.com

4 Graduanda em Agronomia, Departamento de Fitotecnia e Ciências Ambientais, Centro de Ciências Agrárias, Universidade Federal da Paraíba, Campus II, CEP 58397-000, Areia (PB), Brasil. marxcarol48@hotmail.com

5 Graduando do curso de Licenciatura em Ciências Biológicas, Departamento de Ciências Fundamentais e Sociais, Centro de Ciências Agrárias, Universidade Federal da Paraíba, Campus II, CEP 58397-000, Areia (PB), Brasil. brunoufpb10.1@gmail.com

Recebido para publicação em 14/09/2013 e aceito em 13/11/2014

Ci. Fl., v. 26, n. 3, jul.-set., 2016 


\section{INTRODUÇÃO}

A espécie florestal Platymiscium floribundum Vog., pertencente à família Fabaceae, conhecida popularmente por sacambu, jacarandádo-litoral, jacarandá-rosa e jacarandá-vermelho, é uma espécie característica da floresta pluvial da encosta atlântica, que, devido à intensa floração com coloração amarela, pode ser utilizada como planta ornamental e no paisagismo como também em reflorestamentos mistos, reposição de áreas degradadas e de preservação permanente, pois habita quase que exclusivamente o interior da floresta primária densa, nas planícies aluviais, várzeas úmidas e início de encostas (LORENZI, 2009).

Durante a germinação ocorre uma sequência de processos fisiológicos que são influenciados tanto pela temperatura, quanto pela presença e ausência de luz, dessa forma, torna-se necessário estudar a influência desses fatores para compreender o processo germinativo dos diferentes grupos ecológicos que elas pertencem (FERREIRA et al., 2007). Em ambientes naturais, as sementes podem ser encontradas sob diferentes regimes de luz e temperatura, as quais podem variar de acordo com a estrutura do dossel e o seu posicionamento no estádio sucessional da floresta (JESUS e PINARODRIGUES, 1991). As sementes de espécies pioneiras fotoblásticas respondem com germinação plena apenas quando são submetidas à luz vermelha, enquanto as pertencentes aos outros grupos ecológicos, como as secundárias e as clímax, têm a capacidade de germinar à sombra do dossel, sem luz solar direta (KAGEYAMA e VIANA, 1991). A temperatura ótima é favorável para a porcentagem de germinação máxima em menor espaço de tempo, enquanto as temperaturas máxima e mínima são pontos em que as sementes germinam pouco ou não germinam (MAYER e POLJAKOFF-MAYBER, 1989).

As sementes de Peltophorum dubium Taub não apresentaram diferença na porcentagem de germinação, quando expostas à luz branca, vermelha, vermelha extrema e ausência de luz (PEREZ et al., 1999). As sementes da espécie Aspidosperma polyneuron. M. Arg. germinaram nos regimes de luz branca e vermelha distante, sob as temperaturas constantes de 25 e $30^{\circ} \mathrm{C}$ e alternada de $20-30^{\circ} \mathrm{C}$ (SAKITA et al., 2007) e as sementes de Clitoria fairchildiana germinam tanto na presença como na ausência de luz (ALVES et al., 2012).
O interesse sobre o conhecimento das espécies nativas, como também a finalidade econômica ou conservacionista, tem aumentado, assim, o objetivo nesse estudo foi estudar a influência da luz e temperatura na germinação de sementes de Platymiscium floribundum.

\section{MATERIAL E MÉTODOS}

\section{O experimento foi conduzido no Laboratório} de Análise de Sementes (LAS), pertencente ao Departamento de Fitotecnia e Ciências Ambientais, do Centro de Ciências Agrárias, da Universidade Federal da Paraíba (CCA - UFPB), no município de Areia - PB.

As sementes de Platymiscium floribundum foram obtidas de frutos em início do processo de deiscência natural, colhidos em árvores-matrizes no mesmo município. Após a colheita, os frutos foram levados para o Laboratório de Análise de Sementes, mantidos à sombra para secagem natural durante oito dias e, em seguida abertos manualmente com auxílio de uma tesoura para a retirada das sementes, as quais foram tratadas com o fungicida Captan, na concentração de 240/100.000 Kg-1 de sementes, e submetidas a determinações e testes descritos a seguir.

O teor de água das sementes foi determinado pelo método padrão da estufa a $105 \pm$ $3^{\circ} \mathrm{C}$, conforme prescrições das Regras para Análise de Sementes (BRASIL, 2009), com quatro amostras de 10 sementes, sendo os resultados expressos em porcentagem.

Para cada tratamento foram utilizadas 100 sementes, divididas em quatro subamostras de 25 . $\mathrm{O}$ teste foi realizado em câmaras de germinação do tipo Biochemical Oxigen Demand (B.O.D.) ajustadas às temperaturas constantes de $25 \mathrm{e}$ $30^{\circ} \mathrm{C}$ e alternada de $20-30^{\circ} \mathrm{C}$. Os regimes de luz estabelecidos na pesquisa foram luz branca, verde, vermelha e vermelha distante, em regime de 8 horas com luz (período diurno) e 16 horas sem luz (período noturno) e escuro (ausência total de luz branca). Na simulação das condições de luz foram confeccionados sacos com papel celofane, nos quais para a luz branca os rolos foram cobertos com duas folhas transparentes; para a cor verde cobertos com duas folhas verdes, para a luz vermelha cobertos com duas folhas vermelhas; para a luz vermelha distante cobertos com duas folhas vermelhas, intercaladas com uma azul; enquanto que a ausência de luz foi obtida cobrindo-se os rolos com sacos plásticos 
pretos.

O teste de germinação foi conduzido utilizando-se 100 sementes, as quais foram divididas em quatro repetições de 25 , sendo distribuídas sobre duas folhas de papel-toalha, cobertas com uma terceira e organizadas em forma de rolo. $\mathrm{O}$ papel-toalha foi umedecido com água destilada na quantidade equivalente a 2,5 vezes a massa do papel seco, sendo as contagens do número de sementes germinadas aos seis e finalizando aos 14 dias após a semeadura, quando se verificou a estabilização da germinação. O critério utilizado nas avaliações foi o de plântulas normais, ou seja, aquelas com as estruturas essenciais perfeitas (BRASIL, 2009).

A primeira contagem de germinação foi conduzida conjuntamente com o teste de germinação, constando da contagem de plântulas normais aos seis dias após a semeadura, sendo os resultados expressos em porcentagem. Para este teste foram realizadas contagens diárias, no mesmo horário, dos seis aos 14 dias após a semeadura das plântulas normais, sob luz de segurança verde e o índice foi calculado utilizando-se a fórmula proposta por Maguire (1962). O critério utilizado nas avaliações foi o de plântulas normais, ou seja, aquelas com as estruturas essenciais perfeitas (BRASIL, 2009). Após a contagem final do teste de germinação, aos 14 dias de semeadura, as plântulas normais de cada tratamento e repetição foram medidas a raiz e a altura da parte aérea com auxílio de uma régua graduada em centímetros, sendo os resultados expressos em $\mathrm{cm} /$ plântula $^{-1}$. As mesmas plântulas da avaliação anterior foram colocadas em sacos de papel kraft e levadas à estufa regulada a $65^{\circ} \mathrm{C}$, até atingir peso constante (48 horas) e, decorrido esse período, as amostras foram pesadas em balança analítica com precisão de $0,001 \mathrm{~g}$, sendo os resultados expressos em $\mathrm{g} /$ plântula $^{-1}$. $\mathrm{O}$ delineamento experimental utilizado foi inteiramente ao caso, com os tratamentos distribuídos em esquema fatorial 5 × 3 (regimes de luz e temperaturas), em quatro repetições de 25 sementes. Os dados obtidos foram submetidos à análise de variância e as médias comparadas pelo teste Scott-Knott, a 5\% de probabilidade.

\section{RESULTADOS E DISCUSSÃO}

O teor de água das sementes de Platymiscium floribundum no momento da instalação do experimento encontrava-se em $9 \%$.

$\mathrm{Na}$ avaliação entre os regimes de luz e temperaturas, houve interação para todas as variáveis avaliadas, exceto para a altura da parte aérea. Na porcentagem de germinação de sementes de Platymiscium floribundum (Tabela 1), verificouse que, na temperatura de $25^{\circ} \mathrm{C}$, a germinação maiores foram nos regimes de luz branca, verde, vermelha e vermelha distante, enquanto na condição de escuro contínuo foi significativamente inferior. Com relação à temperatura de $30^{\circ} \mathrm{C}$, obtiveram-se os resultados superiores de germinação quando as sementes foram submetidas à luz branca. Andrade et al. (2000), estudando o comportamento germinativo de sementes de jenipapo, conseguiram os maiores resultados nas temperaturas de 25,30 e $35^{\circ} \mathrm{C}$ constantes. No entanto, Silva et al. (2002) avaliando o comportamento de sementes de aroeira observaram que as mesmas quando submetidas à alternância de temperatura revelaram ser indiferentes à luz e que a interação entre os dois fatores não foi significativa para a porcentagem de germinação, semelhante ao que foi observado nesse estudo, no qual se pode observar que a temperatura de $20-30^{\circ} \mathrm{C}$ foi prejudicial nos regimes de luz empregados para as sementes da espécie Platymiscium floribundum causando uma redução na porcentagem de germinação (Tabela 1). A alternância de temperatura pode inibir parcialmente, o desenvolvimento do processo de germinação, resultados encontrados em sementes de Cedrela odorata L. (ANDRADE e PEREIRA 1994). As espécies que crescem sob dossel ou cobertura vegetal densa, geralmente não requerem muita luz, enquanto que outras espécies que se desenvolvem em locais abertos, sem vegetação, exigem quantidades relativamente maiores de luz para que ocorra a germinação (BORGHETTI e FERREIRA, 2004). Observando os regimes de luz dentro de cada temperatura, pode-se verificar que a luz branca se destacou entre os demais regimes de luz, podendo-se deduzir que as sementes de Platymiscium floribundum em ambiente natural conseguem germinar em condições de luminosidade. As observações em campo verificaram maior ocorrência em locais mais iluminados, o que sugere ser esta uma espécie que apresenta especificidade à luz para a germinação das sementes e para o desenvolvimento das plantas (FIGLIOLIA e TAKAKI, 2007). A adaptação das espécies à luminosidade ambiental é importante, principalmente na fase juvenil, por habituar-se às novas condições na sua estrutura, determinando o sucesso de acordo com sua capacidade de adaptação às condições de luminosidade ambiental, cujo 
conhecimento é chave importante para compreensão das florestas e seu manejo (MACIEL, 2002).

Pelos dados da primeira contagem de germinação das sementes de Platymiscium floribundum (Tabela 1) realizada no sexto dia após a semeadura, verifica-se que houve interação significativa entre os regimes de luz e temperaturas. Os maiores percentuais de germinação ocorreram na temperatura de $25^{\circ} \mathrm{C}$ quando considerados os regimes de luz branca e vermelha.

Esses resultados estão de acordo com Borges e Rena (1993) que relataram que a luz branca tem efeito semelhante ao da luz vermelha, devido à composição espectral e características do fitocromo. Os maiores resultados na temperatura de $30^{\circ} \mathrm{C}$ foram verificados em todos os regimes de luz, exceto na sua ausência, fato semelhante ao que ocorreu no teste de geminação. Segundo Nakagawa, (1999), o teste da primeira contagem avalia indiretamente a velocidade de germinação, isso significa que umas sementes germinaram mais rápido do que outras. Os resultados na temperatura de $20-30^{\circ} \mathrm{C}$ indicaram que os regimes de luz branca e verde favoreceram na primeira contagem de germinação. Observando os regimes de luz dentro de cada temperatura, a luz branca favoreceu porcentagem de germinação independentemente da temperatura empregada. Avaliando-se o teste de primeira contagem de germinação de sementes de Leucaena leucocephala Lam. ocorreu menor vigor na temperatura de $35^{\circ} \mathrm{C}$ na ausência de luz (OLIVEIRA, 2008).

$\mathrm{Na}$ Tabela 3 estão dispostos os dados referentes ao índice de velocidade de germinação de sementes de Platymiscium floribundum obtidos nos diferentes tratamentos de regimes de luz e temperaturas. Verificou-se que na temperatura de $25^{\circ} \mathrm{C}$ em todos os regimes de luz empregados proporcionaram resultados superiores na porcentagem de germinação. Quando as sementes foram submetidas à temperatura de $30^{\circ} \mathrm{C}$ merece destaque a luz branca, enquanto na temperatura de $20-30^{\circ} \mathrm{C}$ destacou-se o regime de luz branca e o de vermelha distante que propiciaram índices mais elevados. Comparando-se a porcentagem de germinação dentro dos regimes de luz, verificou-se que os maiores percentuais de germinação foi sob o regime de luz branca em todas as temperaturas. Segundo Borges e Rena (1993), a faixa entre 20

TABELA 1: Germinação, primeira contagem de germinação de sementes de Platymiscium floribundum submetidas a diferentes regimes de luz e temperaturas.

TABLE 1: Germination, first count of germination of of Platymiscium floribundum under different light regimes and temperatures.

\begin{tabular}{|c|c|c|c|}
\hline \multirow{2}{*}{ Regimes de luz } & \multicolumn{3}{|c|}{ Temperaturas $\left({ }^{\circ} \mathrm{C}\right)$} \\
\hline & 25 & 30 & $20-30$ \\
\hline \multicolumn{4}{|c|}{ Germinação (\%) } \\
\hline Branca & $85 \mathrm{aA}$ & $88 \mathrm{aA}$ & $77 \mathrm{bB}$ \\
\hline Verde & $83 \mathrm{aA}$ & $77 \mathrm{aB}$ & $66 \mathrm{bB}$ \\
\hline Vermelha & $83 \mathrm{aA}$ & $68 \mathrm{bC}$ & $46 \mathrm{cD}$ \\
\hline Vermelha distante & $87 \mathrm{aA}$ & $69 \mathrm{bC}$ & $61 \mathrm{cC}$ \\
\hline Escuro & $69 \mathrm{aB}$ & $52 \mathrm{cD}$ & $60 \mathrm{bC}$ \\
\hline \multicolumn{4}{|l|}{ C.V.(\%) 6.95} \\
\hline & \multicolumn{3}{|c|}{$\begin{array}{l}\text { Primeira contagem de } \\
\text { germinação }(\%)\end{array}$} \\
\hline Branca & $68 \mathrm{aA}$ & $67 \mathrm{aA}$ & $62 \mathrm{aA}$ \\
\hline Verde & $61 \mathrm{aB}$ & $59 \mathrm{aA}$ & $68 \mathrm{aA}$ \\
\hline Vermelha & $68 \mathrm{aA}$ & $63 \mathrm{aA}$ & $45 \mathrm{bC}$ \\
\hline Vermelha distante & $57 \mathrm{aB}$ & $64 \mathrm{aA}$ & $55 \mathrm{aB}$ \\
\hline Escuro & $43 \mathrm{aC}$ & $37 \mathrm{aB}$ & $37 \mathrm{aC}$ \\
\hline
\end{tabular}

C.V.(\%) 10.52

Em que: Médias seguidas de mesma letra, minúscula na coluna e maiúscula na linha, não diferem estatisticamente entre si, a 5\% de probabilidade pelo teste de Scott-Knott. 
TABELA 3: Índice de velocidade de germinação de sementes de Platymiscium floribundum submetidas a diferentes regimes de luz e temperaturas.

TABLE 3: Speed rate of germination of Platymiscium floribundum under different light regimes and temperatures.

\begin{tabular}{lccc}
\hline \multirow{2}{*}{ Regimes de luz } & \multicolumn{3}{c}{ Temperaturas $\left({ }^{\circ} \mathrm{C}\right)$} \\
\cline { 2 - 4 } & 25 & 30 & $20-30$ \\
\hline Branca & $2,27 \mathrm{aA}$ & $2,32 \mathrm{aA}$ & $2,04 \mathrm{aA}$ \\
Verde & $2,00 \mathrm{aA}$ & $1,94 \mathrm{aB}$ & $1,36 \mathrm{bB}$ \\
Vermelha & $2,04 \mathrm{aA}$ & $1,90 \mathrm{aB}$ & $1,08 \mathrm{bB}$ \\
Vermelha distante & $2,02 \mathrm{aA}$ & $1,81 \mathrm{aB}$ & $1,81 \mathrm{aA}$ \\
Escuro & $1,85 \mathrm{aA}$ & $1,18 \mathrm{bC}$ & $1,36 \mathrm{bB}$ \\
\hline
\end{tabular}

C.V.(\%) 13.12

Em que: Médias seguidas de mesma letra, minúscula na coluna e maiúscula na linha, não diferem estatisticamente entre si, a 5\% de probabilidade pelo teste de Scott-Knott

a $30^{\circ} \mathrm{C}$ é a mais adequada para a germinação de grande número de espécies tropicais e subtropicais. Portanto, a espécie Platymiscium floribundum apresenta grande plasticidade ecológica, revelando a capacidade de germinar em diferentes condições ambientais, o que garante o sucesso em seu habitat natural, que estão sujeitas a altas irradiâncias e grandes variações de temperatura (FIGLIOLIA e TAKAKI, 2007). As sementes Erythrina verna são indiferentes à luz e germinam em uma faixa ampla de temperatura, sendo a faixa ótima entre 20 e $25^{\circ} \mathrm{C}$ (DEMUNER et al., 2008).

O crescimento inicial do comprimento da raiz das plântulas de Platymiscium floribundum foi observado na temperatura constante de $25^{\circ} \mathrm{C}$, nos regimes de luz branca $(3,50 \mathrm{~cm})$ e vermelha distante, $(4,50 \mathrm{~cm})$ enquanto na temperatura de $30^{\circ} \mathrm{C}$, foram obtidos maiores comprimentos da raiz primária nos regimes de luz vermelha distante e na ausência de luz contínuo $(3,80 \mathrm{~cm})$, respectivamente. Para os efeitos na temperatura alternada $20-30^{\circ} \mathrm{C}$, pode-se verificar que os maiores comprimentos da raiz de plântulas foram atingidos nas sementes submetidas a luz branca, verde, vermelha e escuro contínuo (Tabela 4). O comprimento médio da raiz de plântulas normais da espécie Parkia pendula nas temperaturas 25 e $30^{\circ} \mathrm{C}$ foi de $(4 \mathrm{~cm})$, enquanto na temperatura de $35^{\circ} \mathrm{C}$, em que o comprimento foi de $3 \mathrm{~cm}$ (ROSSETO et al., 2009). A temperatura alternada de $20-30^{\circ} \mathrm{C}$, proporcionou maiores comprimento da raiz de Clitoria fairchildiana no regime de luz vermelha distante (Alves et al., 2012).

Ao analisar a altura da parte aérea de plântulas de Platymiscium floribundum, verificou- se que houve efeito isolado para os fatores regimes de luz e temperaturas. Verificando apenas efeito da temperatura, cujos maiores comprimentos ocorreram na temperatura de $30^{\circ} \mathrm{C}$, enquanto nos regimes de luz ocorreu sob luz branca (Tabela 4). Portela (2001) verificou que comprimentos de raízes de sombreiro das mudas em pleno sol apresentaram valores inferiores aos das mudas sob o sombreamento. O comprimento do hipocótilo de Jacaranda copaia obteve melhores médias nas temperaturas de 25 e $30^{\circ} \mathrm{C}$ com 3,42 e $3,26 \mathrm{~cm}$, respectivamente (ABENSUR et al., 2007). Na altura da parte aérea das plântulas de Clitoria fairchildiana, os maiores valores foram alcançados na temperatura de $25^{\circ} \mathrm{C}$ sob luz branca, verde, vermelha, vermelha distante e escuro (ALVES et al., 2012).

Os maiores conteúdos de massa seca das raízes de Platymiscium floribundum foram encontrados nas plântulas oriundas de sementes submetidas a temperaturas de $25^{\circ} \mathrm{C}$ nos regimes de luz verde, branca, vermelha, vermelha distante e escuro. $\mathrm{Na}$ temperatura de $30^{\circ} \mathrm{C}$, os melhores resultados foram obtidos nos regimes de luz branca, verde e escuro e os resultados referentes à temperatura de $20-30^{\circ} \mathrm{C}$ no escuro foram inferiores aos demais regimes de luz. Observando os regimes de luz dentro de cada temperatura, destacou-se como maior conteúdo de massa seca da raiz de plântulas no regime de luz verde (Tabela 6). Provavelmente, ocorreu maior transferência de reservas dos tecidos de armazenamento e maior agrupamento destas reservas pelo eixo embrionário quando as necessidades para ocorrer à germinação são supridas, as sementes vigorosas originam plântulas 
TABELA 4: Comprimento da raiz primária, altura da parte aérea de plântulas de Platymiscium floribundum oriundas de sementes submetidas a diferentes regimes de luz e temperaturas.

TABLE 4: Primary root length, shoot length of seedlings of Platymiscium floribundum from seeds under different light regimes and temperatures.

\begin{tabular}{lccc}
\hline \multirow{2}{*}{ Regimes de luz } & \multicolumn{3}{c}{ Temperaturas $\left({ }^{\circ} \mathrm{C}\right)$} \\
\cline { 2 - 4 } & \multicolumn{3}{c}{30} \\
\hline Branca & Comprimento da raiz primária & $20-30$ \\
Verde & $3,50 \mathrm{aA}$ & $3,07 \mathrm{aB}$ & $2,55 \mathrm{aA}$ \\
Vermelha & $2,85 \mathrm{aB}$ & $3,00 \mathrm{aB}$ & $3,11 \mathrm{aA}$ \\
Vermelha distante & $2,54 \mathrm{aB}$ & $2,86 \mathrm{aB}$ & $2,01 \mathrm{aA}$ \\
Escuro & $4,20 \mathrm{aA}$ & $3,85 \mathrm{aA}$ & $2,42 \mathrm{bA}$ \\
\hline
\end{tabular}

C.V.(\%) 19.72

Altura da parte aérea $(\mathrm{cm})$

\begin{tabular}{lc}
\hline \multicolumn{1}{c}{ Temperaturas e Regimes de luz } & Médias \\
\hline $25,30,20-30^{\circ} \mathrm{C}$ & $4,56 \mathrm{~b} ; 4,91 \mathrm{a} ; 4,97 \mathrm{a}$ \\
Branca & $4,99 \mathrm{a}$ \\
Verde & $4,62 \mathrm{~b}$ \\
Vermelha & $5,28 \mathrm{a}$ \\
Vermelha distante & $4,87 \mathrm{a}$ \\
Escuro & $4,30 \mathrm{~b}$ \\
\hline
\end{tabular}

C.V. (\%) 8.98

Em que: Médias seguidas de mesma letra, minúscula na coluna e maiúscula na linha, não diferem estatisticamente entre si, a 5\% de probabilidade pelo teste de Scott-Knott.

com maior índice de crescimento (NAKAGAWA, 1999).

A luz solar quando filtrada pelas folhas verdes tem sua distribuição espectral alterada devido à absorção seletiva das folhas, especialmente pelas clorofilas (SMITH, 2000).

$\mathrm{Na}$ avaliação da massa seca da parte aérea das plântulas de Platymiscium floribudum, quando as sementes foram submetidas à temperatura de $25^{\circ} \mathrm{C}$, os regimes de luz empregados não foram satisfatórios para essa variável. Entretanto, quando as sementes foram submetidas à temperatura de $30^{\circ} \mathrm{C}$, os maiores conteúdos de massa seca foram obtidos nos regimes de luz vermelha e vermelha distante.

TABELA 6: Massa seca de raízes de plântulas oriundas de sementes de Platymiscium floribundum submetidas a diferentes regimes de luz e temperaturas.

TABLE 6: Dry weight of roots of seedlings from seeds of Platymiscium floribundum under different light regimes and temperatures.

\begin{tabular}{lccc}
\hline \multirow{2}{*}{ Regimes de luz } & \multicolumn{3}{c}{ Temperaturas $\left({ }^{\circ} \mathrm{C}\right)$} \\
\cline { 2 - 4 } & 25 & 30 & $20-30$ \\
\hline Branca & $0,0047 \mathrm{bC}$ & $0,0072 \mathrm{aA}$ & $0,0070 \mathrm{aA}$ \\
Verde & $0,0072 \mathrm{aA}$ & $0,0062 \mathrm{aA}$ & $0,0067 \mathrm{aA}$ \\
Vermelha & $0,0077 \mathrm{aB}$ & $0,0055 \mathrm{bA}$ & $0,0082 \mathrm{aA}$ \\
Vermelha distante & $0,0060 \mathrm{bA}$ & $0,0060 \mathrm{bA}$ & $0,0075 \mathrm{aA}$ \\
Escuro & $0,0045 \mathrm{aC}$ & $0,0050 \mathrm{aA}$ & $0,0057 \mathrm{aB}$ \\
\hline
\end{tabular}

C.V(\%) 13.85

Em que: Médias seguidas de mesma letra, minúscula na coluna e maiúscula na linha, não diferem estatisticamente entre si, a 5\% de probabilidade pelo teste de Scott-Knott. 
TABELA 7: Massa seca da parte aérea de plântulas oriundas de sementes de Platymiscium floribundum submetidas a diferentes regimes de luz e temperaturas.

TABLE 7: Dry mass of the aerial part of seedlings from seeds of Platymiscium floribundum under different light regimes and temperatures.

\begin{tabular}{lccc}
\hline \multirow{2}{*}{ Regimes de luz } & \multicolumn{3}{c}{ Temperaturas $\left({ }^{\circ} \mathrm{C}\right)$} \\
\cline { 2 - 4 } & 25 & 30 & $20-30$ \\
\hline Branca & $0,0170 \mathrm{bA}$ & $0,0207 \mathrm{aB}$ & $0,0227 \mathrm{aA}$ \\
Verde & $0,0155 \mathrm{cA}$ & $0,0217 \mathrm{bB}$ & $0,0247 \mathrm{aA}$ \\
Vermelha & $0,0170 \mathrm{bA}$ & $0,0242 \mathrm{aA}$ & $0,0220 \mathrm{aA}$ \\
Vermelha distante & $0,0170 \mathrm{bA}$ & $0,0232 \mathrm{aA}$ & $0,0240 \mathrm{aA}$ \\
Escuro & $0,0167 \mathrm{cA}$ & $0,0210 \mathrm{bB}$ & $0,0237 \mathrm{aA}$ \\
\hline
\end{tabular}

C.V $(\%) 7.90$

Em que: Médias seguidas de mesma letra, minúscula na coluna e maiúscula na linha, não diferem estatisticamente entre si, a 5\% de probabilidade pelo teste de Scott-Knott.

Já na temperatura de $20-30^{\circ} \mathrm{C}$, constataram-se as maiores produções de massa seca da parte aérea em todos os regimes de luz empregados. Observando os regimes de luz dentro de cada temperatura foi possível observar que as sementes germinaram satisfatoriamente nos regimes de luz vermelha e vermelha distante. $\mathrm{O}$ conteúdo de massa seca da parte aérea das plântulas Clitoria fairchildiana ocorreu na temperatura de $25^{\circ} \mathrm{C}$ nos regimes de luz branca, verde e escuro (ALVES et al. 2012).

\section{CONCLUSÃO}

As sementes de Platymiscium floribundum germinam na presença de luz, sendo consideradas fotoblásticas positivas. Para avaliação do vigor dessas sementes, recomenda-se a temperatura de $25^{\circ} \mathrm{C}$ no regime de luz branca.

\section{REFERÊNCIAS BIBLIOGRÁFICAS}

ABENSUR, F.O. et al. Tecnologia de sementes e morfologia da germinação de Jacaranda copaia D. Don (Bignoniaceae). Revista Brasileira de Biociências, Porto Alegre v.5, n.2, p.60-62, 2007.

ALVES, M.M. et al. Potencial fisiológico de sementes de Clitoria fairchildiana R. A. Howard. - Fabaceae submetidas a diferentes regimes de luz e temperatura. Ciência Rural, Santa Maria, v.42, n.12, p. 2199-2205, 2012.

ANDRADE, A.C.S. et al. Germinação de sementes de jenipapo: temperatura, substrato e morfologia do desenvolvimento pós-seminal. Pesquisa Agropecuária Brasileira, Brasília, v.35, n.3, p.609-615, 2000.

ANDRADE, A.C.S.; PEREIRA, T.S. Efeito do substrato e da temperatura na germinação e no vigor de sementes de cedro - Cedrela odorata L. (Meliaceae). Revista Brasileira de Sementes, v.16, n.1, p.34-40, 1994.

BORGES, E.E.L.; RENA, A.B. Germinação de sementes. In: AGUIAR, I.B.; PIÑA-RODRIGUES, F.C.M.; FIGLIOLIA, M.B. (Coord.) Sementes florestais tropicais. Brasília: ABRATES, p.83-136. 1993p.

BORGHETTI, F.; FERREIRA, A. G. (orgs.). Germinação: do básico ao aplicado. Porto Alegre: Artmed, 2004. $323 \mathrm{p}$.

BRASIL. Ministério da Agricultura, Pecuária e abastecimento. Regras para análise de sementes. Secretaria de Defesa Agropecuária. Brasília: MAPA/ ACS, 2009. 395p.

CARVALHO FILHO, J.L.S. et al. Produção de mudas de jatobá (Hymenaea courbaril L) em diferentes ambientes e composições de substratos. Cerne, Lavras, v.9, n.1, p.109-118, 2003.

DEMUNER, V.G. et al. Influência da luz e da temperatura na germinação de sementes de Erythrina verna (Leguminosae, Papilionoideae). Museu de Biologia Professor Mello Leitão, n. 24, p. 101-110, 2008.

FERREIRA, C. A. R.; FIGLIOLIA, M. B.; ROBERTO, L. P. C. Ecofisiologia da germinação de sementes de Calophyllum brasiliensis Camb. Instituto Florestal Série Registros, São Paulo, n.31, p.173-178, 2007.

FIGLIOLIA, M.B.; TAKAKI, M. Desenvolvimento de mudas de Platymiscium floribundum Vog. 
(sacambu) Fabaceae sob diferentes condições de luz, em viveiro. In: $58^{\circ}$ Congresso Nacional de Botânica, São Paulo. 2007.

JESUS, R. M.; PIÑA-RODRIGUES, F. C. M. Programa de produção e tecnologia de sementes florestais da Florestas Rio Doce S.A.: uma discussão dos resultados obtidos. In: SIMPÓSIO BRASILEIRO SOBRE TECNOLOGIA DE SEMENTES FLORESTAIS, 2., 1989, Atibaia. Anais... São Paulo: Instituto Florestal, 1991. p. 59-86.

KAGEYAMA, P.Y.; VIANA,V.M. Tecnologia de sementes e grupos ecológicos de espécies arbóreas tropicais. In: SIMPÓSIO BRASILEIRO SOBRE TECNOLOGIA DE SEMENTES FLORESTAIS, 2., 1989, Atibaia. São Paulo: Intituto Florestal, 1991.p.197-215.

LORENZI, H. Árvores brasileiras: manual de identificação e cultivo de plantas arbóreas do Brasil. Instituto Plantarum, Nova Odessa, 2009. 3.ed. v. 1. 384p.

MACIEL, M.N.M. et al. Efeito da radiação solar na dinâmica de uma floresta. Revista de Ciências Exatas e Naturais, Guarapuava, v.4, n.1, p.101-114, 2002.

MAGUIRE, J.D. Speed of germination aid in selection and evaluation for seedling emergence and vigour. Crop Science, Madison, v.2, n.2, p.176-177, 1962.

MAYER, A.C; POLJAKOFF-MAYER, A. The germination of seeds.4.ed. Oxford: Pergamon Press, 1989. 270p.

NAKAGAWA, J. Testes de vigor baseados no desempenho das plântulas. In: KRZYZANOSWKI, F. C.; VIEIRA, R. D.; FRANÇA NETO, J. B. (Ed.).
Vigor de sementes: conceitos e testes. Londrina: ABRATES, 1999. p. 2.1-2.24.

OLIVEIRA, A.B. Germinação de sementes de leucena (Leucaena leucocephala (Lam.) De Wit.), var. K-72. Revista de Biologia e Ciências da Terra, Campina Grande, v.8, n.2, p.166-172, 2008.

PEREZ, S.C.J.G.A.; FANTI, S.C.; CASALI, C.A. Dormancy break and light quality effects on seed germination of Peltophorum dubium Taub. Revista Árvore, Viçosa, v.23, n.2, p.131-137, 1999.

PORTELA, R.C.Q.; SILVA, I.L.; RODRIGUES, F.C.M.P. Crescimento inicial de mudas de Clitoria fairchildiana Howard e Peltophorum dubium (Sprenge) Taub em diferentes condições de sombreamento Ciência Florestal, Santa Maria, v.11, n.2, p. 163-170 2001.

ROSSETO, J. et al. Germinação de sementes de Parkia pendula (Willd.) Benth. ex Walp. (Fabaceae) em diferentes temperaturas. Revista Árvore, Viçosa, v.33, n.1, p.47-55, 2009.

SAKITA, A.E.N.; SILVA,A.; PAULA, R.C. Germinação de sementes de Aspidosperma polyneuron M. Arg. (peroba-rosa) sob diferentes condições de qualidades de luz e temperatura. Instituto Florestal Série Registros, n. 31, p. 203-207, 2007.

SILVA, L.M.M.; RODRIGUES, T.J.D.; AGUIAR, I.B. Efeito da luz e da temperatura na germinação de sementes de aroeira (Myracrodruon urundeuva Allemão). Revista Árvore, Viçosa, v. 26, n. 6, p. 691-697, 2002.

SMITH, H. Phytochromes and light signal perception by plants - an emerging synthesis. Nature, London, v. 407,2000 , p. $585-591$. 